\title{
Insecticidal factors from the seeds of Erythrina indica Lam against Hyblaea puera, the most serious defoliator pest of teak
}

\author{
Deepa B.*1 and Remadevi O. K. ${ }^{2}$ \\ ${ }^{1}$ Forest and Wood Protection Division, Institute of Wood Science \& Technology, Karnataka, India \\ ${ }^{2}$ Environmental Management \& Policy Research Institute, Doresanipalya Forest Campus, Bangalore, \\ India
}

Date Received: 10-03-2017

Date Accepted: 10-05-2017

\begin{abstract}
The organic solvent extracts from the seeds of Erythrina indica were tested for their insecticidal action against Hyblaea puera, the most important defoliator pest of teak. The larvicidal activity of the petroleum ether, chloroform, methanol, ethyl alcohol, ethyl acetate, acetone and water extracts from the seeds of $E$. indica on the $3^{\text {rd }}$ instar larvae of $H$. puera showed $100 \%$ mortality even with least concentration $(0.25 \%)$. The ovicidal activity was exhibited by chloroform and ethyl acetate extract. Both the extracts exhibited highest egg hatch inhibition (56\%) at highest concentration (2\%). The least $\mathrm{LC}_{50}(1.15 \%)$ shows that ethyl acetate extract is better than chloroform extract (1.78). Two compounds were isolated from the ethyl acetate extract of the seeds of Erythrina indica by column chromatography. The compounds were identified using HPLC, GC MS, and NMR. Compound 1 was a mixture of linoleic acid and oleic acid. Compound 2 was a mixture of linoleic acid and oleic acid ester with a glycerol unit attached to it. Compounds 1 and 2 were biologically active and exhibited potent insecticidal activity against the $3^{\text {rd }}$ instar larvae of $H$. puera. The result showed that Compound 2 isolated from E. indica exhibited highest mortality $(72 \%)$ at concentration $(0.125 \%)$. At highest concentration $(0.5 \%)$ highest mortality $(92 \%)$ was exhibited by Compound 2 which on comparison is on par with the Neemark (Azadirachtin) exhibiting highest mortality (100\%). The study is complementary with earliar works and proves that the seeds of $E$. indica has immense potential to be utilized as botanical insecticide.
\end{abstract}

\section{Keywords}

Erythrina indica, Seeds, Fatty acids, Triglycerides, Insecticidal, Hyblaea puera

\section{Introduction}

Erythrina indica Lam. Syn. Erythrina variegata var.orientalis (L.) Merr. commonly known as Tiger's claw, Indian coral tree and sunshine tree in India belongs to the family Fabaceae. It is distributed along the sea coasts of India and also widely grown as shade tree in coffee plantations. It is also commonly available in Sri Lanka and Malaysia. This is a moderate-sized tree, the trunk is armed with numerous prickles and bears bright cinnamon red flowers. Flowering is from March to April. Young leaves and tender shoots are eaten as vegetable (Gunjatkar and Vartak, 1982). The leaves are laxative, diuretic, antihelmintic, galactagogue and emmenagogue. They are applied externally for dispersing venereal buboes and for relieving pain in joints. The fresh leaves are used for the relief of ear ache and as anodyne

*Correspondence: deepa_balan2002@rediffmail.com

Tel: +919448803195

ISSN 2235-9370 Print / ISSN 2235-9362 Online (C2017 University of Sri Jayewardenepura 
in tooth ache, the juice is also used to kill worms in sores (WOI, 1952). The chemical constituent isolated is Hypaphorine. This study was taken up with the objective of testing the insecticidal action of the organic solvent extracts of the seeds of E. indica on Hyblaea puera, as the test insect. The study further involves isolation of insecticidal fatty acids and triglycerides from the ethyl acetate extract of the seeds of $E$. indica.

\section{Materials and methods}

\section{Collection of plant material and preparation of extracts}

The seeds of E. indica were collected from tumkur in Karnataka, India. The seeds were shade dried. The dried seeds were powdered in a pulverizer. $100 \mathrm{~g}$ of the plant material was dissolved in $250 \mathrm{ml}$ of each of the solvent namely petroleum ether, chloroform, methanol, ethyl alcohol, ethyl acetate, acetone and water and kept for 48 hours in sealed round bottom flasks. After 48 hours, it was extracted in soxhlet apparatus until the eluting solvent turned colourless. The solvent was evaporated in a rotavapour and the dry crude extract obtained was weighed and stored in refrigerator.

\section{Phytochemical analysis}

Based on the bioassay, it was ascertained that the ethyl acetate extract of the seeds of $E$. indica were very effective as contact toxicants. Hence, this extract were taken for detailed phytochemical analysis to find out the active ingredient responsible for the biological activity.

\section{Analytical HPLC}

The crude ethyl acetate extract of E. indica seed was subjected to reversed- phase HPLC to detect the compounds of interest. The column used was Rp 18-Reversed phase column with $25 \mathrm{~cm}$ in length and $4.6 \mathrm{~mm}$ in diameter. $1 \mathrm{mg}$ of the crude extract was injected into the column. Two solvent systems were used namely, methanol-water (9:1) and acetonitrile-water (9:1) with flow rate of $1 \mathrm{ml} / \mathrm{min}$ and column pressure up to $180 \mathrm{psi}$. UV detection of compounds of interest was done at $215 \mathrm{~nm}$. The solvent elution gradient is given in (Table 1).

Table 1: Solvent Elution Gradient of HPLC

\begin{tabular}{|l|l|}
\hline \multicolumn{1}{|c|}{ Time (min) } & Concentration $(\mathrm{A}) \%$ \\
\hline 0.01 & 100 \\
\hline 5 & 80 \\
\hline 10 & 60 \\
\hline 15 & 40 \\
\hline 20 & 20 \\
\hline 25 & 0 \\
\hline 35 & 0 \\
\hline 40 & 100 \\
\hline
\end{tabular}

\section{Column chromatography}

The crude ethyl acetate extract of the seeds of E. indica $(10 \mathrm{~g})$ were purified further to obtain compounds of interest. A vertical glass column was packed with a suspension of silica gel (20g) (70-325 mesh) using hexane as solvent. The column was eluted with solvent gradually starting from $100 \%$ hexane followed by increasing order of ethyl acetate in hexane (0-100\%) (Table 2). 
Table 2: Solvent Elution Gradient for E. indica

\begin{tabular}{|l|l|l|l|}
\hline \multicolumn{1}{|c|}{$\%$ of solvent eluted } & Fraction & $\begin{array}{c}\text { Volume of solvent } \\
\text { used }\end{array}$ & \multicolumn{1}{|c|}{ TLC mobile phase } \\
\hline $100 \%$ hexane & $1-16$ & $800 \mathrm{ml}$ & $20 \%$ EtOAc/ Hexane \\
\hline $2 \%$ EtOAc/ Hexane & $17-42$ & $1000 \mathrm{ml}$ & $20 \%$ EtOAc/ Hexane \\
\hline $5 \%$ EtOAc/ Hexane & $43-50$ & $400 \mathrm{ml}$ & $20 \%$ EtOAc/ Hexane \\
\hline $8 \%$ EtOAc / Hexane & $51-60$ & $500 \mathrm{ml}$ & $20 \%$ EtOAc/ Hexane \\
\hline $10 \%$ EtOAc / Hexane & $61-73$ & $600 \mathrm{ml}$ & $20 \%$ EtOAc/ Hexane \\
\hline $15 \%$ EtOAc / Hexane & $74-94$ & $800 \mathrm{ml}$ & $20 \%$ EtOAc/ Hexane \\
\hline $20 \%$ EtOAc / Hexane & $94-115$ & $1000 \mathrm{ml}$ & $20 \%$ EtOAc/ Hexane \\
\hline $30 \%$ EtOAc / Hexane & $116-125$ & $500 \mathrm{ml}$ & $40 \%$ EtOAc/ Hexane \\
\hline $50 \%$ EtOAc / Hexane & $126-134$ & $500 \mathrm{ml}$ & $60 \%$ EtOAc/ Hexane \\
\hline $100 \%$ Ethyl acetate & $135-145$ & $500 \mathrm{ml}$ & $10 \% \mathrm{MeOH/CHCl3}$ \\
\hline
\end{tabular}

EtOAc-Ethyl acetate, $\mathrm{MeOH}-\mathrm{Methanol,} \mathrm{CHCl}_{3-}$ Chloroform

\section{Structure Elucidation of the active components}

The structural information of the isolated compounds were done using nuclear magnetic resonance (NMR) and mass spectroscopy (MS) techniques.

Nuclear Magnetic Resonance Spectroscopy

To elucidate the structure of the two isolated compounds, $1 \mathrm{D}$ NMR $\left({ }^{1} \mathrm{H}\right.$ NMR and $\left.{ }^{13} \mathrm{C} \mathrm{NMR}\right)$ spectra were recorded on AMX $400 \mathrm{MHz}$ instrument using TMS (tetramethylsilane) as internal standard.

\section{Mass spectroscopy}

To determine the molecular weight, the sample was subjected to ESIMS (Electron Spray Ionization quadrupole Mass Spectrometry) in Bruker Esquire 3000 plus. Source conditions were set as: Voltage $4 \mathrm{KV}$, Nitrogen sheath (Nebulizer) gas pressure $10 \mathrm{psi}$, heated capillary temperature $250^{\circ} \mathrm{C}$, full scan $50 \mathrm{~m} / \mathrm{z}$ to $1050 \mathrm{~m} / \mathrm{z}$, dry gas flow $5 \mathrm{~L} / \mathrm{min}$.

\section{Preparation of the test concentrations from the crude extract}

A known amount of crude extract obtained from the above process was dissolved in respective solvent in 1:1 proportion and serially diluted with water to obtain the desired concentrations of $0.25 \%$, $0.5 \%, 1 \%, 2 \%$ and $4 \%$. One drop of emulsifier $(0.005 \%$ ) (Tween 20, Sigma Chemical Company) was added to the extract to ensure complete dispersion of the active ingredient.

Rearing of the test insect

Hyblaea puera Cramer (Lepidoptera: Hyblaeidae) is the most important defoliator pest of teak in India. Outbreaks occur almost every year in India, over extensive areas. During these outbreaks which occur 
mainly during the early flushing period of teak, trees usually suffer total defoliation. The insect culture was maintained following a standard methodology (Nair, et al., 1998). The pupae were brought to the laboratory and maintained in glass bottles covered with muslin cloth. The emerging adults were kept in cages overnight and then kept as pairs in separate glass bottles for mating. They were provided with $10 \%$ honey solution for feeding. The adults usually mated on the first or second day of emergence and started laying eggs from the third night onwards. The eggs were laid on the cloth covering the bottles. The eggs were washed in $0.5 \%$ sodium hypochlorite solution for 10 minutes. After air-drying, the eggs were kept for emergence in glass bottles along with freshly collected tender teak leaves, sprayed with $0.5 \%$ sodium hypochlorite and air-dried. The larvae were kept in glass bottles along with fresh leaves and covered with muslin cloth. In each glass bottle 20 - 40 larvae were kept depending upon the instar. On moulting, larvae were changed to fresh bottles. On pupation, the pupae were removed and transferred to sterilized glass bottles. Insect culture was maintained in the laboratory at $28^{\circ} \mathrm{C}$ and $16 \mathrm{~L}: 8 \mathrm{D}$ photoperiod and at $85 \%$ humidity. To maintain hygienic conditions the entire culture area was often sterilized with $70 \%$ alcohol. The glassware's were sterilized with formalin after each wash.

\section{Contact toxicity with crude extract}

To evaluate the contact toxicity effects of crude extracts of all the plants selected for study, two bioassays namely, larvicidal action and ovicidal action were conducted.

\section{Larvicidal action with crude extract}

For bioassays to evaluate larvicidal action of crude extracts early $3^{\text {rd }}$ instar larvae of $H$. puera of uniform age and weight range $(9-13 \mathrm{mg})$ obtained from laboratory culture were used. Contact toxicity was tested with $0.25 \%, 0.5 \%, 1 \%, 2 \%$ and $4 \%$ concentrations. Five replications with 10 individuals each were used for each concentration. Larvae were introduced into sterilized plastic petriplates. The test solutions were applied on larvae, as topical spray using a TLC (Thin Layer Chromatography) sprayer. The petriplates were covered with the lid. In blank group the larvae were sprayed with water and in the control group the larvae were sprayed with respective solvent. Tween 20 also served as a control. Observations were made on the behaviour of the larvae and mortality was observed at $2 \mathrm{hr}, 4 \mathrm{hr}$ and $6 \mathrm{hr}$.

\section{Ovicidal action}

12-hour-old eggs were carefully taken on a small piece of muslin cloth using fine camel hair brush. 5 replications with 5 eggs each were used for the experiment. The extract was prepared at a concentration of $2 \%, 1 \%$ and $0.5 \%$. It was sprayed on the egg using a micropipette. The cloth with the eggs after complete drying was introduced into glass vials and covered with muslin cloth. Treatment with water and respective solvents served as control. The eggs were observed for hatching after 48 hours.

\section{Larvicidal action with the purified fractions}

The test compounds, two from the ethyl acetate extract of the seeds of E. indica were tested for their larvicidal action on the $3^{\text {rd }}$ instar larvae of $H$. puera. The desired concentration of test solution $0.5 \%$, $0.25 \%, 0.125 \%, 0.0625 \%$ of $2.5 \mathrm{ml}$ each was prepared. One drop of emulsifier $(0.005 \%)$ (Tween 20, Sigma Chemical Company) was added with the extract to ensure complete dispersion of the active ingredient in water. The test compounds from $E$. indica were dissolved in $\mathrm{CDCl}_{3}$ (deuterochloroform). For comparison, bioassay was performed with commercially available Neemark (Azadirachtin 0.03\%) was used.

To evaluate the toxic effects of purified compounds, larvicidal action was studied on $3^{\text {rd }}$ instar larvae of $H$. puera. Contact toxicity was tested with $0.5 \%, 0.25 \%, 0.125 \%, 0.0625 \%$ concentration. Five replications of 10 individuals each were used for each concentration. Larvae were introduced into sterilized plastic petriplates. The test solutions were applied on the dorsum of the insects as topical 18 
application using a micropipette. Each larva received $10 \mu \mathrm{l}$ of the test solution. The petriplates were covered with the lid. In the blank group, the larvae were applied with water and the control group with respective solvent. Tween 20 also served as a control. Mortality was observed at $2 \mathrm{hr}, 4 \mathrm{hr}$ and $6 \mathrm{hr}$ after application.

Statistical Analysis of the data

Percentage of larval mortality was calculated. The data was subjected to analysis of variance (ANOVA) and the means separated using Least Significant Difference (LSD). (Lethal concentration) LC 50 were calculated using probit analysis according to calculations outlined in Finney (1971). Probit analysis was carried out using SPSS Software program version 12 and Anova was done with AGRES statistical package.

\section{Results and discussion}

\section{Larvicidal action}

The larvicidal activity of the seeds of E. indica against the $3^{\text {rd }}$ instar larvae of $H$. puera did not vary among the different extracts. All the treatments were significantly different from the control. The larvae showed restless movement on spraying, had nervous tremors and convulsions and then became inactive and finally death ensued. The dead larvae became rigid. The extracts of E. indica had rapid action and the death occurred within two hours of spraying. All the extracts were highly effective causing $100 \%$ mortality even with least concentration $(0.25 \%)$. The estabishment of the insecticidal property of the seeds of E. indica is supported by the study of Chandrakantha (1988), wherein seed extract was reported to be toxic to the larvae and the pupae of the pulse beetle $C$. maculates.

Table 3: Ovicidal activity of various extracts of $E$. indica

\begin{tabular}{|l|c|c|r|}
\hline \multirow{2}{*}{ Treatment } & \multicolumn{3}{|c|}{ Concentration in \% } \\
\cline { 2 - 4 } & 2 & 1 & 0.5 \\
\hline Ethyl acetate & $56.00 \pm 43.35(48.45)$ & $52.00 \pm 22.80(46.15)$ & $36.00 \pm 35.77(36.87)$ \\
\hline Chloroform & $56.00 \pm 38.47(48.45)$ & $32.00 \pm 36.33(34.45)$ & $32.00 \pm 22.80(34.45)$ \\
\hline Control & $0.00(0.00)$ & $0.00(0.00)$ & $0.00(0.00)$ \\
\hline & SED & $\mathrm{CD}(0.05)$ & $\mathrm{CD}(0.01)$ \\
Treatment & 0.62361 & 1.28707 & 1.75390 \\
Concentration & 0.76376 & 1.57633 & 2.14808 \\
$\mathrm{~T} * \mathrm{C}$ & 1.08012 & 2.22927 & 3.03785 \\
\hline
\end{tabular}

\section{Ovicidal action}

The ovicidal activity of the seed extracts of $E$. indica varied among the different extracts. All the treatments did not show any activity and were on par with control except chloroform and ethyl acetate extract. Both the extracts exhibited highest egg hatch inhibition (56\%) at highest concentration $(2 \%)$ 
(Table 3). The least $\mathrm{LC}_{50}(1.15 \%)$ shows that ethyl acetate extract is better than chloroform extract (1.78) (Table 4). The study is supported by the finding of Ghatak and Bhusan (1995 a and b) that the seeds of $E$. indica produced $100 \%$ hatch inhibition to eggs of Corcyra cephalonica and S. oblique.

Mean \pm SD represents mean percentage mortality of 5 replicates with 5 individuals each.Means followed by the same alphabet does not differ significantly at 5\% level of significance. Values within parentheses are angular transformed values.

Table 4: Dose - mortality response of $H$. puera on contact toxicity with $E$. indica.

\begin{tabular}{|l|r|c|c|c|}
\hline Treatment & LC 50 & Slope \pm S.E & Intercept \pm SE & Chi-square \\
\hline $\begin{array}{l}\text { Ethyl acetate } \\
\text { extract }\end{array}$ & 1.15 & $0.84333 \pm 0.59627$ & $-0.05154 \pm 0.14593$ & 0.249 \\
\hline $\begin{array}{l}\text { Chloroform } \\
\text { extract }\end{array}$ & 1.78 & $1.04236 \pm 0.60490$ & $-0.26085 \pm 0.14835$ & 0.943 \\
\hline
\end{tabular}

The Chi-square value is less than $3.841(\mathrm{Df}=1)$ is not significant $(\mathrm{P}>0.05)$.

Fruits of Solanum indicum and E. indica were found to be effective in the laboratory against the aphid of rose, Macrosiphum rosae (Verma and Srivastava, 1988). E. indica seed extract was reported to be toxic to the larvae and the pupae of the pulse beetle $C$. maculates and it showed antifeedant property to the adult beetles (Chandrakantha, 1988). Srinivasaperumal (1990) studied the effect of ether extract of E. indica seed against larvae of $P$. ricini. Senthamizhselvan and Muthukrishnan (1992) tested ether extract of E.indica seeds on the Ergolis merione, Porthesia scintillans and Spodoptera exigua which caused larval mortality and the damage was decreased by $65 \%$ following the treatment with the highest concentration of each extract. Ovicidal properties of the crude extracts of 8 indigenous plants namely A. indica, E. indica, Piper nigrum, A. calamus, Adenocalymna allicea, Thevetia neriifolia, Pachyrhizus erosus and Annona squamosa were evaluated in the laboratory on eggs of Corcyra cephalonica and Spilosoma obliqua showed that E. indica possess ovicidal action (Ghatak and Bhusan, 1995a and b).

Phytochemical analysis

Based on the contact toxicity of the tested extracts, ethyl acetate extract of the seeds of E. indica was subjected to analytical HPLC to detect the number of compounds present in the crude extract and thereafter to column chromatography for isolation of the active components.

\section{Analytical HPLC}

The ethyl acetate extract of the seeds of E. indica when incorporated for detection of compounds, through Reversed phase HPLC system on Rp-18 column, maintained at a wave length of $215 \mathrm{~nm}$ and flow rate of $1 \mathrm{ml} / \mathrm{min}$ using twin solvent system (water / methanol and water /acetonitrile) reveals a series of compounds eluting at different retention times.

In the chromatographical estimation, since the concentration of sample is directly proportional to peak area, the detected compounds are explained as follows. The chromatogram (Fig. 1) (Table 5) of $E$. indica shows that the peaks eluted at a retention time (11.15 minutes) and (36.29 minutes) have maximum concentration $(7.86 \%)$ and $(9.89 \%)$. It is therefore concluded that there are two major components in the ethyl acetate extract of $E$. indica seeds. 


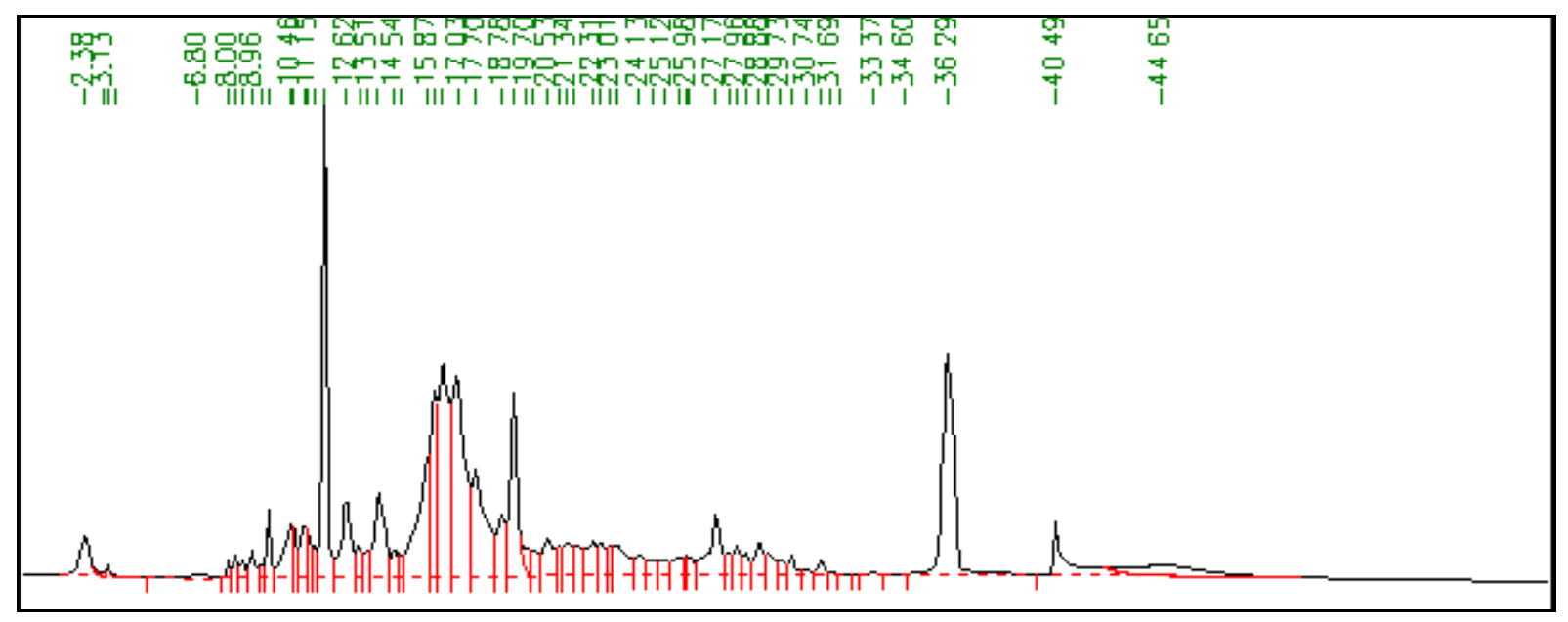

Figure 1: Ethyl acetate extract of seed of E. indica with water/ methanol as elutents

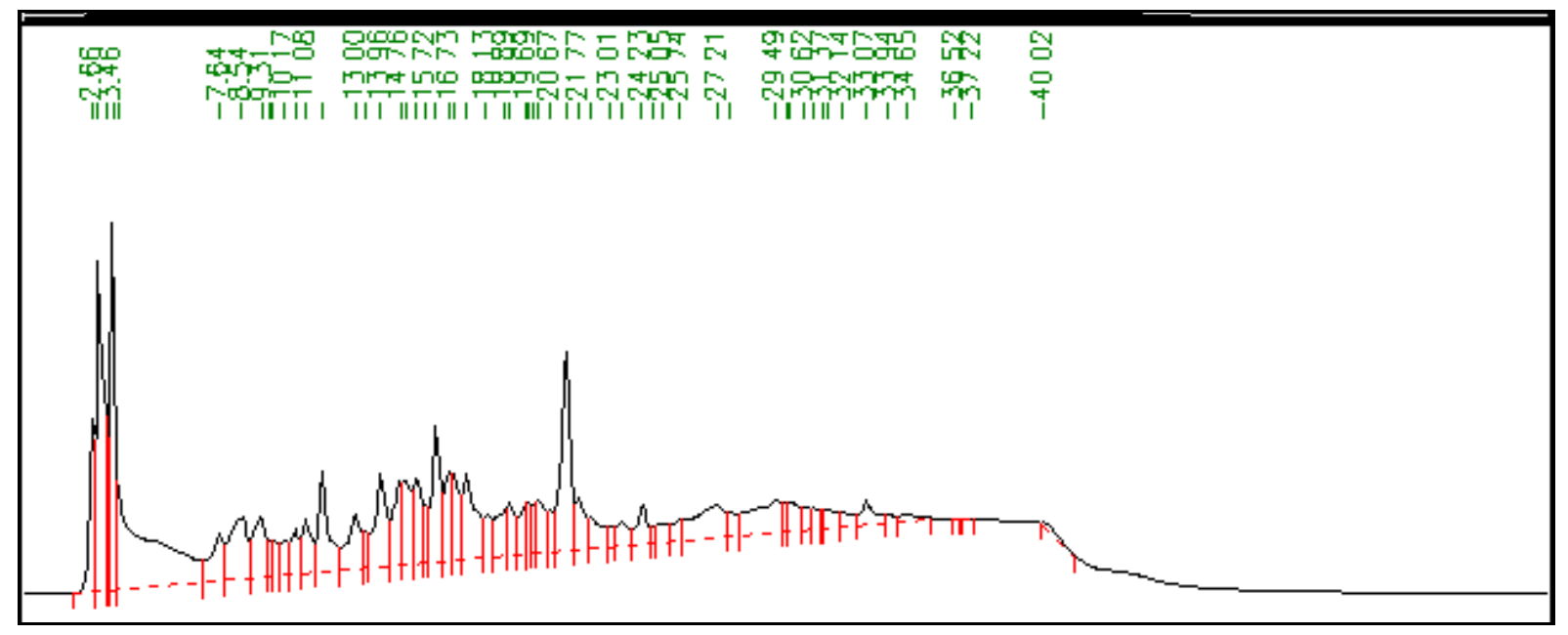

Figure: 2 Ethyl acetate extract of seed of E. indica with water/ acetonitrile as elutents 
Table 5: Retention time and peak area (\%) of compounds from E. indica

\begin{tabular}{|c|c|}
\hline Retention time (Min.) & Peak area $(\%)$ \\
\hline 3.1 & 0.1 \\
\hline 3.3 & 0.13 \\
\hline 3.5 & 0.05 \\
\hline 6.8 & 0.37 \\
\hline 8 & 0.21 \\
\hline 8.2 & 0.34 \\
\hline 8.5 & 0.35 \\
\hline 8.9 & 0.59 \\
\hline 9.3 & 0.2 \\
\hline 9.6 & 0.92 \\
\hline 10.4 & 1.66 \\
\hline 10.5 & 0.87 \\
\hline 11 & 1.17 \\
\hline 11.7 & 7.86 \\
\hline 12.6 & 2.86 \\
\hline 13.1 & 0.74 \\
\hline 13.5 & 0.52 \\
\hline 13.8 & 30.02 \\
\hline 14.5 & 0.62 \\
\hline 15.8 & 5.07 \\
\hline 16.1 & 4.4 \\
\hline 16.4 & 8.6 \\
\hline 17 & 8.9 \\
\hline 17.6 & 5.1 \\
\hline 21 & 0.5 \\
\hline 21.3 & 1.11 \\
\hline 21.5 & 0.91 \\
\hline 22.3 & 1.32 \\
\hline 22.6 & 0.81 \\
\hline 27.17 & 2.55 \\
\hline 28.8 & 0.92 \\
\hline 36.2 & 9.89 \\
\hline 40.4 & 2.69 \\
\hline 44.6 & 2.86 \\
\hline
\end{tabular}

It was further confirmed when water/ acetonitrile was used as solvent system, which shows that the peaks eluted at a retention time (3.46 minutes) and (20.67 minutes) have maximum concentration (Figure 2).

\section{Column chromatography}

Chromatographic column separation of the ethyl acetate fraction of the E. indica seeds resulted in the isolation of two compounds. Both the compounds were eluted with $20 \%$ Ethyl acetate/ Hexane. 
Compound $1\left(320 \mathrm{mg}, \mathrm{R}_{\mathrm{f}} 0.76\right)$ was isolated as a pale yellow fluid. Compound $2\left(185 \mathrm{mg}, \mathrm{R}_{\mathrm{f}} 0.55\right)$ was also isolated as yellow fluid.

\section{Structure elucidation of the active principle}

The structure of the two compounds was elucidated by using NMR and Mass spectroscopy. The ${ }^{1} \mathrm{H}$ NMR and ${ }^{13} \mathrm{C}$ NMR assignments were obtained by extensive use of ${ }^{1} \mathrm{D}$ NMR techniques.

Compound 1: ${ }^{1} \mathrm{H}$ NMR (400 MHz, $\left.\mathrm{CDCl}_{3}\right) 0.95$ (m, 3H), 1.29 (bs, $\left.14 \mathrm{H}\right), 1.62$ (m, 2H), 2.00 (m, 4H), $2.32(\mathrm{~m}, 2 \mathrm{H}), 2.35(\mathrm{~m}, 2 \mathrm{H}), 4.36(\mathrm{~m}, 2 \mathrm{H}), 4.12(\mathrm{~m}, 1 \mathrm{H}), 5.30(\mathrm{~m}, 2 \mathrm{H}), 5.40(\mathrm{~m}, 2 \mathrm{H}) .{ }^{13} \mathrm{C}$ NMR $(100$ $\left.\mathrm{MHz}, \mathrm{CDCl}_{3}\right)$ assignment is given in table 6. The spectral data were in agreement with the published data and confirmed that it is a mixture of free fatty acids (Linoleic and oleic acid) (Figure 3).

Table 6: ${ }^{1} \mathrm{H}$ and ${ }^{13} \mathrm{C}-\mathrm{NMR}$ data for Compound 1

\begin{tabular}{|c|c|c|c|}
\hline Carbon & $\delta$ values in ppm & Hydrogen & $\delta$ values in $\mathrm{ppm}$ \\
\hline $\mathrm{C}-1$ & 173.13 & - & \\
\hline $\mathrm{C}-2$ & 34.11 & $\mathrm{H}-2$ & $2.32(2 \mathrm{H}, \mathrm{m})$ \\
\hline $\mathrm{C}-3$ & 25.58 & $\mathrm{H}-3$ & $1.62(2 \mathrm{H}, \mathrm{m})$ \\
\hline $\mathrm{C}-4$ & 29.29 & $\mathrm{H}-4$ & $1.29(2 \mathrm{H}, \mathrm{m})$ \\
\hline $\mathrm{C}-5$ & 29.07 & $\mathrm{H}-5$ & $1.29(2 \mathrm{H}, \mathrm{m})$ \\
\hline C-6 & 29.29 & H-6 & $1.29(2 \mathrm{H}, \mathrm{m})$ \\
\hline $\mathrm{C}-7$ & 31.48 & $\mathrm{H}-7$ & $1.29(2 \mathrm{H}, \mathrm{m})$ \\
\hline $\mathrm{C}-8$ & 33.96 & $\mathrm{H}-8$ & $2.00(2 \mathrm{H}, \mathrm{m})$ \\
\hline C-9 & 130.09 & $\mathrm{H}-9$ & $5.40(1 \mathrm{H}, \mathrm{m})$ \\
\hline $\mathrm{C}-10$ & 127.86 & H-10 & $5.30(1 \mathrm{H}, \mathrm{m})$ \\
\hline C-11 & 33.96 & H-11 & $2.35(2 \mathrm{H}, \mathrm{m})$ \\
\hline $\mathrm{C}-12$ & 128.04 & H-12 & $5.40(1 \mathrm{H}, \mathrm{m})$ \\
\hline C-13 & 129.91 & H-13 & $5.30(1 \mathrm{H}, \mathrm{m})$ \\
\hline $\mathrm{C}-14$ & 33.96 & H-14 & $2.00(2 \mathrm{H}, \mathrm{m})$ \\
\hline C-15 & 29.65 & H-15 & $1.29(2 \mathrm{H}, \mathrm{m})$ \\
\hline C-16 & 32.72 & H-16 & $1.29(2 \mathrm{H}, \mathrm{m})$ \\
\hline $\mathrm{C}-17$ & 22.63 & H-17 & $1.29(2 \mathrm{H}, \mathrm{m})$ \\
\hline C-18 & 14.01 & H-18 & $0.95(3 \mathrm{H}, \mathrm{m})$ \\
\hline C-19 & 68.91 & H-19 & $4.36(2 \mathrm{H}, \mathrm{m})$ \\
\hline Glycerol unit & 71.20 & & $4.12(1 \mathrm{H}, \mathrm{m})$ \\
\hline Glycerol unit & 62.11 & & $3.56(2 \mathrm{H}, \mathrm{m})$ \\
\hline
\end{tabular}

Figure 3: Mixture of free fatty acid (linoleic and oleic acid) 
Compound 2: ${ }^{1} \mathrm{H}$ NMR (400 MHz, $\left.\mathrm{CDCl}_{3}\right) \square 0.95$ (m, 3H), 1.29 (bs, $\left.14 \mathrm{H}\right), 1.62$ (m, 2H), 2.00 (m, 4H), $2.32(\mathrm{~m}, 2 \mathrm{H}), 2.35(\mathrm{~m}, 2 \mathrm{H}), 4.36(\mathrm{~m}, 2 \mathrm{H}), 4.12(\mathrm{~m}, 1 \mathrm{H}), 5.30(\mathrm{~m}, 2 \mathrm{H}), 5.40(\mathrm{~m}, 2 \mathrm{H}) .{ }^{13} \mathrm{C} \mathrm{NMR}(100$ $\mathrm{MHz}, \mathrm{CDCl}_{3}$ ) the assignment is given in Table 7. The spectral data were in agreement with the published data and confirmed that it is Triglycerides $(\mathrm{R}=$ Glycerol unit connected to a mixture of Linoleic and oleic acid ester) (Figure 4).

Table 7: ${ }^{1} \mathrm{H}$ and ${ }^{13} \mathrm{C}$ NMR data for Compound 2

\begin{tabular}{|l|l|l|l|}
\hline Carbon & $\boldsymbol{\delta}$ values in ppm & Hydrogen & $\boldsymbol{\delta}$ values in ppm \\
\hline C-1 & 179.85 & - & \\
\hline C-2 & 34.07 & H-2 & $2.32(2 \mathrm{H}, \mathrm{m})$ \\
\hline C-3 & 25.63 & $\mathrm{H}-3$ & $1.62(2 \mathrm{H}, \mathrm{m})$ \\
\hline C-4 & 29.08 & $\mathrm{H}-4$ & $1.29(2 \mathrm{H}, \mathrm{m})$ \\
\hline C-5 & 29.08 & $\mathrm{H}-5$ & $1.29(2 \mathrm{H}, \mathrm{m})$ \\
\hline C-6 & 29.33 & $\mathrm{H}-6$ & $1.29(2 \mathrm{H}, \mathrm{m})$ \\
\hline C-7 & 31.53 & $\mathrm{H}-7$ & $1.29(2 \mathrm{H}, \mathrm{m})$ \\
\hline C-8 & 34.07 & $\mathrm{H}-8$ & $2.00(2 \mathrm{H}, \mathrm{m})$ \\
\hline C-9 & 130.19 & $\mathrm{H}-9$ & $5.40(1 \mathrm{H}, \mathrm{m})$ \\
\hline C-10 & 127.91 & $\mathrm{H}-10$ & $5.30(1 \mathrm{H}, \mathrm{m})$ \\
\hline C-11 & 37.40 & $\mathrm{H}-11$ & $2.35(2 \mathrm{H}, \mathrm{m})$ \\
\hline C-12 & 128.08 & $\mathrm{H}-12$ & $5.40(1 \mathrm{H}, \mathrm{m})$ \\
\hline C-13 & 129.71 & $\mathrm{H}-13$ & $5.30(1 \mathrm{H}, \mathrm{m})$ \\
\hline C-14 & 33.49 & $\mathrm{H}-14$ & $2.00(2 \mathrm{H}, \mathrm{m})$ \\
\hline C-15 & 29.68 & $\mathrm{H}-15$ & $1.29(2 \mathrm{H}, \mathrm{m})$ \\
\hline C-16 & 32.76 & $\mathrm{H}-16$ & $1.29(2 \mathrm{H}, \mathrm{m})$ \\
\hline C-17 & 23.63 & $\mathrm{H}-17$ & $1.29(2 \mathrm{H}, \mathrm{m})$ \\
\hline C-18 & 14.01 & $\mathrm{H}-18$ & $0.95(3 \mathrm{H}, \mathrm{m})$ \\
\hline Glycerol unit & 68.94 & & $4.36(2 \mathrm{H}, \mathrm{m})$ \\
\hline Glycerol unit & 71.20 & & $4.12(1 \mathrm{H}, \mathrm{m})$ \\
\hline Glycerol unit & 62.11 & & $3.56(2 \mathrm{H}, \mathrm{m})$ \\
\hline
\end{tabular}

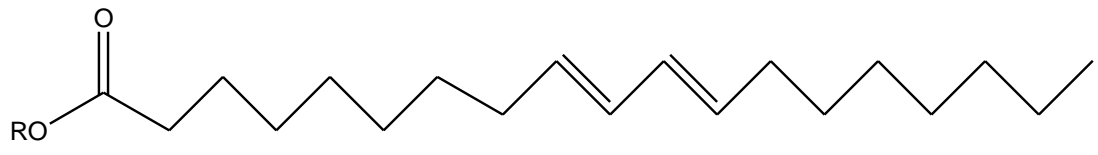

Figure 4: Triglycerides ( $\mathrm{R}=$ Glycerol unit connected to a mixture of Linoleic and oleic acid ester)

\section{Contact toxicity with purified compounds}

The purified compounds from the crude extracts were of meager quantity. Hence, the insecticidal potency of the purified compounds was tested only for larvicidal action by contact toxicity on the $3^{\text {rd }}$ instar larvae of $\mathrm{H}$. puera. The result showed that Compound 2 isolated from E. indica exhibited highest mortality $(72 \%)$ at concentration $(0.125 \%)$. At highest concentration $(0.5 \%)$ highest mortality $(92 \%)$ was exhibited by Compound 2. On comparison with Neemark at higher concentrations compound 2 was on par with the Neemark (Azadirachtin) exhibiting highest mortality (100\%) (Table 8). 
Table 8: Percentage mortality of $3^{\text {rd }}$ instar larvae of $H$. puera on contact toxicity with purified compounds.

\begin{tabular}{|l|l|l|l|l|}
\hline \multirow{2}{*}{ Treatment } & \multicolumn{4}{|c|}{ Concentration in \% } \\
\cline { 2 - 5 } & \multicolumn{1}{|c|}{0.5} & 0.25 & 0.125 & 0.0625 \\
\hline Compound 1 & $\begin{array}{l}82.00 \pm 24.89 \\
(67.59)^{\mathrm{abc}}\end{array}$ & $\begin{array}{l}44.00 \pm 33.62 \\
(41.61)^{\mathrm{cd}}\end{array}$ & $\begin{array}{l}44.00 \pm 15.17 \\
(41.43)^{\mathrm{d}}\end{array}$ & $24.00 \pm 23.02(27.48)^{\mathrm{ef}}$ \\
\hline Compound 2 & $\begin{array}{l}92.00 \pm 13.04 \\
(74.79)^{\mathrm{ab}}\end{array}$ & $\begin{array}{l}78.00 \pm 13.04 \\
(63.13)^{\mathrm{bc}}\end{array}$ & $\begin{array}{l}72.00 \pm 13.04 \\
(58.66)^{\mathrm{c}}\end{array}$ & $44.00 \pm 5.48(41.53)^{\mathrm{d}}$ \\
\hline Azadirachtin & $\begin{array}{l}100.00 \pm 0.00 \\
(80.90)^{\mathrm{a}}\end{array}$ & $\begin{array}{l}100.00 \pm 0.00 \\
(80.90)^{\mathrm{a}}\end{array}$ & $\begin{array}{l}100.00 \pm 0.00 \\
(80.90)^{\mathrm{a}}\end{array}$ & $100.00 \pm 0.00(80.90)^{\mathrm{a}}$ \\
\hline Blank & $0.00(9.10)$ & $0.00(9.10)$ & $0.00(9.10)$ & $0.00(9.10)$ \\
\hline $\begin{array}{l}\text { Control (Respective } \\
\text { solvent) }\end{array}$ & $0.00(9.10)$ & $0.00(9.10)$ & $0.00(9.10)$ & $0.00(9.10)$ \\
\hline Tween 20 & $0.00(9.10)$ & $0.00(9.10)$ & $0.00(9.10)$ & $0.00(9.10)$ \\
\hline
\end{tabular}

$\begin{array}{llcc} & \text { SED } & \text { CD }(0.05) & \text { CD }(0.01) \\ \text { Treatment } & 0.45497 & 0.90545 & 1.20141 \\ \text { Concentration } & 0.40694 & 0.80986 & 1.07458 \\ \text { E*C }^{*} & 0.90995 & 1.81089 & 2.40282\end{array}$

Mean \pm SD represents mean percentage mortality of 5 replicates with 10 individuals each. Means followed by the same alphabet does not differ significantly at 5\% level of significance. Values with parenthesis are arcsine transformed values.

The $\mathrm{LC}_{50}$ values are presented in Table 9. The least $\mathrm{LC}_{50}(0.07 \%)$ exhibits that compound 2 is most effective, followed by compound $1(0.18 \%)$. The result showed that the compounds 1 (mixture of linoleic and oleic acid) and 2 (triglycerides) isolated from the ethyl acetate extract of seed of E. indica are effective. 
Table 9: Dose-mortality responses of $3^{\text {rd }}$ instar larvae of $H$. puera on contact toxicity with purified compounds

\begin{tabular}{|c|c|c|c|l|l|r|}
\hline \multirow{2}{*}{ Treatment } & \multirow{2}{*}{ LC 50 } & \multicolumn{2}{|c|}{ Fiducial limits } & \multirow{2}{*}{ Slope \pm S.E } & Intercept \pm SE & $\begin{array}{c}\text { Chi- } \\
\text { square }\end{array}$ \\
\cline { 3 - 6 } & $\begin{array}{r}\text { Lower } \\
\text { Limit }\end{array}$ & $\begin{array}{c}\text { Upper } \\
\text { Limit }\end{array}$ & & $\begin{array}{l}1.56842 \pm \\
0.28808\end{array}$ & $\begin{array}{l}1.14106 \pm \\
0.2358\end{array}$ & 5.810 \\
\hline Compound 1 & 0.18728 & 0.14158 & 0.25195 & $\begin{array}{l}1.86705 \pm \\
0.28007\end{array}$ & 1.412 \\
\hline Compound 2 & 0.06981 & 0.03934 & 0.09626 & $\begin{array}{l}1.61496 \pm \\
0.31399\end{array}$ & &
\end{tabular}

The Chi-square value is less than $5.991(\mathrm{Df}=2)$ is not significant $(\mathrm{P}>0.05)$.

* The Chi-square value is more than $5.991(\mathrm{Df}=2)$ is significant $(\mathrm{P}<0.05)$.

Insecticidal activity of fatty acid constituents isolated from the seeds of $D$. palustris is reported by Ramsewak et al. (2001) against $A$. aegyptii. Insecticidal activity of oleic and linoleic acid against $C$. maculates showed ovicidal and oviposition deterrent activity. Though the insecticidal activity of $E$. indica seed is reported, the study of larvicidal and ovicidal activity of linoleic acid and oleic acid isolated from the seeds of E. indica against H. puera is reported for the first time. Deshpande et al.(1974) reported oleic and linoleic acid as insecticidal components from this plant, which were found to be toxic to the pulse beetle, Callosobruchus chinensis.

The triglycerides and fatty acids obtained from other plant sources have been shown to have pesticidal or insect growth regulatory activities, but to our knowledge this is the first report of biolological activity of triglycerides and fatty acids isolated from the seeds of Erythrina indica showing insecticidal property against the larvae of Hyblaea puera.

\section{Conclusions}

Thus the study proves that the seeds of E. indica has immense potential to be utilized as botanical insecticide. At present, there is ever increasing demand for botanical based insecticide. Further scientific validation, chemical profiling of the seeds of E. indica and extensive field trials is required to practically utilize the seeds of E. indica for developing marketable botanical insecticide.

\section{Acknowledgement}

The first author acknowledges University Grants Commission, India for financial assistance. The authors are thankful to Director, Institute of Wood Science \& Technology for infrastructure and Kerala Forest Research Institute for helping in bioassay.

\section{References}

Gunjatkar N, Vartak VD. 1982. Enumeration of wild legumes from Pune district, Maharashtra. Journal of Economic and taxonomic botany, 3:1-9

A Dictionary of Indian Raw materials and industrial products. 1952. In WOI (The wealth of India); Publication and information Directorate, CSIR, New Delhi, India. III (D-E): 30. 
Nair KSS, Varma RV, Sudheendrakumar VV, Mohandas K, Mohamed Ali MI. 1998. Management of the teak defoliator (Hyblaea puera) using nuclear polyhedrosis virus (NPV). In KFRI Research report, 151: 8-9.

Chandrakantha J. 1988. Effect of plant chemicals on food utilization in Callosobruchus maculates. In Abstract of III national Symp. On Nutritional Ecology of Insects and Environment, S.D. (PG) College, Muzaffarnagar (UP): 25.

Ghatak SS, Bhusan TK. 1995a. Evaluation on the ovicidal activity of some indigenous plant extracts on rice moth, Corcyra cephalonica Staint. (Galleriidae: Lepidoptera). Environment and Ecology, 13(2): 284-266.

Ghatak SS, Bhusan TK. 1995b. Evaluation on the ovicidal activity of some indigenous plant extracts on Bihar hairy caterpillar, Spilosoma oblique (Wk.) (Arctiidae: Lepidoptera). Environment and Ecology, 13(2): 294-296.

Verma RR, Srivastava PS. 1988. Toxicity of some plant extracts to rose aphid Macrosiphum rosae. Progressive horticulture, 20(1-2): 181-182.

Srinivasaperumal S, Muthukrishnan J, Palavesam A. 1990. Effect of plant chemicals on in vivo protease activity and food utilization in the armyworm Pericallia ricini (Fab.) (Arctiidae: Lepidoptera). Proceedings of the Indian national Science Academy Part B, Biological Sciences, 56(5-6): 389395.

Senthamizhselvan M, Muthukrishnan J. 1992. Effect of plant chemicals on food consumption of three lepidopteran larvae. Insect science and its application, 13(3), 429-434.

Ramsewak RS, Nair MG, Murugesan S, Mattson WJ, Zasada J. 2001. Insecticidal fatty acids and triglycerides from Dirca palustris. J. Agric. Food. Chem, 49: 5852-5856.

Deshpande R S, Adhikary P S, Tipris NP. 1974. Stored grain pest control agents from Nigella sativa and Pogostemon heyneamus. Bull. Grain. Tech., 12: 232-234. 